\title{
Russian students' awareness of and attitudes toward donating to biobanks
}

\author{
Larissa A. Tsvetkova, Ksenia Y. Eritsyan*, Natalia A. Antonova \\ Saint Petersburg State University, Saint Petersburg, Russia
}

${ }^{*}$ Corresponding author. E-mail: ksenia.eritsyan@gmail.com

\begin{abstract}
Today in Russia and all over the world significant efforts are invested in building biobanks-specialized facilities for storing biological materials for research and medical purposes. The successful functioning of biobanks depends directly on people's willingness to donate their biological materials. No previous studies of people's attitudes toward donations to biobanks have been undertaken in Russia. The goal of this study was to measure attitudes toward biobank donation among young Russians and to evaluate potential sociodemographic and personality factors that play a role in a person's readiness to become a donor. Data from 542 students at Saint Petersburg State University were collected from group-administered paper-and-pencil questionnaires. Only one-fifth of the students knew about the existence of biobanks, while roughly the same number believed they might have heard something about them but were not absolutely certain. However, the students indicated a relatively high level of readiness to become biobank donors (74\%). Willingness to be a biobank donor was correlated significantly with studying biology and was just modestly correlated with students' values. In addition, we found gender-specific differences in the biobank characteristics that students felt were important in making a decision about whether to donate. The study demonstrated that today the attitudes of the general population (at least, those of the subgroup studied, students) do not pose a problem for the further development of biobanking in Russia.
\end{abstract}

Keywords: biobank, public attitude, public opinion, awareness, Rokeach Values Survey, university students, cross-sectional

\section{Introduction}

A biobank is a specialized facility that stores for research and medical purposes both biological materials (such as samples of blood, saliva, urine, DNA, and bone marrow) and relevant information about the donors of these materials (physical, behavioral, and sociopsychological characteristics). Biobanks are an important public health resource because of their relevance for carrying out medical and biological research, for solving problems of forensic medicine, and for developing 
new methods of diagnostics and treatment, as well as for reaching other goals (O’Doherty \& Hawkins, 2010; Riegman et al., 2008; Serepkaite, Valuckiene, \& Gefenas, 2014; Sudlow et al., 2015; Thompson \& Willeit, 2015).

The successful functioning of biobanks depends directly on people's willingness to donate their biological materials for purposes of research and storage. Therefore, the availability of voluntary donors is the cornerstone of any biobanking system (Gaskell \& Gottweis, 2011). In fact, every country that has tried to establish such a system has evaluated the extent to which different groups among the general population were ready to make such a donation as well as the key factors people consider when deciding to become a donor.

Russia has made several attempts to establish specialized biobanks (Buikin, 2012), and there is sufficient reason to believe that these practices will continue. However, so far no attempts have been made in Russia to study people's attitudes toward this particular type of biological donation. The lack of such information could jeopardize the proliferation of biobanks in the future.

At the same time, this phenomenon, which is still a novelty in Russia, is interesting from the point of view of psychology because its psychological context is not entirely clear. Should we view the psychological significance of biobanking donation as a variation on donations in the wider sense of the word, as its usefulness for other people is not quite obvious? Or are some other mechanisms in play?

The goals of this study were to look at attitudes toward biobank donation among young Russians by using St. Petersburg State University students as subjects and to evaluate potential sociodemographic and personality factors playing a role in a person's readiness to become a donor.

According to the normative theory of altruism, values are one of the most significant predictors of altruism, along with norms and a sense of moral obligation (Feigin, Owens, \& Goodyear-Smith, 2014). In its turn, altruism is one of the main motivating factors in the decision to become a biobank donor (Kettis-Lindblad, Ring, Viberth, \& Hansson, 2006). Therefore, one of the goals of this study was to look at the correlation between a person's readiness to become a biobank donor and that individual's value orientations.

\section{Method}

Data were collected as part of a larger monitoring study of the lifestyles and health attitudes of students at St. Petersburg State University in October 2014. In order to guarantee the representative nature of the study, stratified sampling was used. During the first stage, proportional nonsystematic sampling was used, taking into consideration education specialization: humanities vs. natural sciences. Out of a total of 22 departments, 3 natural sciences departments and 3 humanities departments were chosen randomly. During the second stage, total sampling of all courses was used. During the third stage, proportional nonsystematic sampling was used: only those students who happened to be on the university premises on the day of the survey filled out the questionnaire.

Most of data were collected by group-administered paper-and-pencil questionnaires. Participants filled in the questionnaires anonymously in the classroom with 
the research coordinators functioning as survey leaders. Participation was voluntary and did not involve monetary compensation; no identification information was collected. Participants were told that they could leave the form blank if they decided not to participate in the study. If they decided to participate, they had to sign an informed-consent form.

A total of 542 questionnaire forms met the criteria for statistical processing. Among the interviewees, 163 (30.1\%) were male and 379 (69.9\%) were female. The average age was $19.5 \pm 2$ years old.

The questionnaire consisted of several parts. This article looks at some of these parts, in particular those that correlate the most with the goals of the study:

(1) Awareness of and attitudes toward becoming a biobank donor: being aware of the term; having a notion of one's willingness to become a biobank donor; and evaluating the validity of various factors in making such a decision. This was the definition of biobank given in the questionnaire: "A biobank is a specialized facility for storing biological materials, for example, samples of blood, saliva, urine, or DNA, for scientific and medical purposes. Imagine that you are asked to provide samples of your blood (urine, saliva, etc.) that in the future will be used to study the nature of various diseases."

(2) The terminal values set of the Rokeach Value Survey. The students were asked to choose from a general list $(N=18)$ not more than five values that they found the most significant.

(3) Self-evaluation of various qualities and personality traits. The informants evaluated their qualities (for example, sexual appeal, ability to withstand hardships, ability to fulfill the requirements of the learning process) on a scale of 1 to 7 , where 7 stands for the maximum degree of any given quality and 1 stands for the complete lack of the quality.

(4) Evaluation of one's satisfaction with various aspects of one's life. The informants evaluated to what degree they were satisfied with their relationships (vis-à-vis classmates, professors, parents), their financial situation, their sexual relationships, and the psychological atmosphere in the department in which they were studying, on a scale of 1 to 5 , where 1 means "completely unsatisfied" and 5 means "completely satisfied."

(5) Sociodemographic characteristics: sex, age, department and year of study, religious affiliation, marital status, having children.

Data analysis included calculation of the frequency distributions of the variables of interest for every university department and for the entire sample. In order to assess correlations between key variables that characterize attitudes toward becoming a biobank donor and sociodemographic and personality factors, the Pearson chi-squared test or Student's t-test was used. All the variables that indicated the existence of a significant correlation with attitudes toward biobanking in a binary model at the significance level $<0.1$ were entered into the logistic regression model. All statistical analyses were performed using SPSS version 16. 


\section{Results}

\section{Awareness of biobanking}

Only one-fifth of the students (21.1\% (17.6-24.5)) knew about the existence of biobanks, while roughly the same number believed they might have heard something about them but were not absolutely certain (19.6 (16.2-22.9)). The highest degree of awareness was demonstrated by the students who were studying biological disciplines $(38.5 \%(28.8-48.3))$, while the least informed students were those studying mathematics $(8.8 \%(2.6-14.9))(p \leq 0.001)$. As for the humanities, the percentage of students who had heard the term biobank was about $16-22 \%$ (Figure 1).

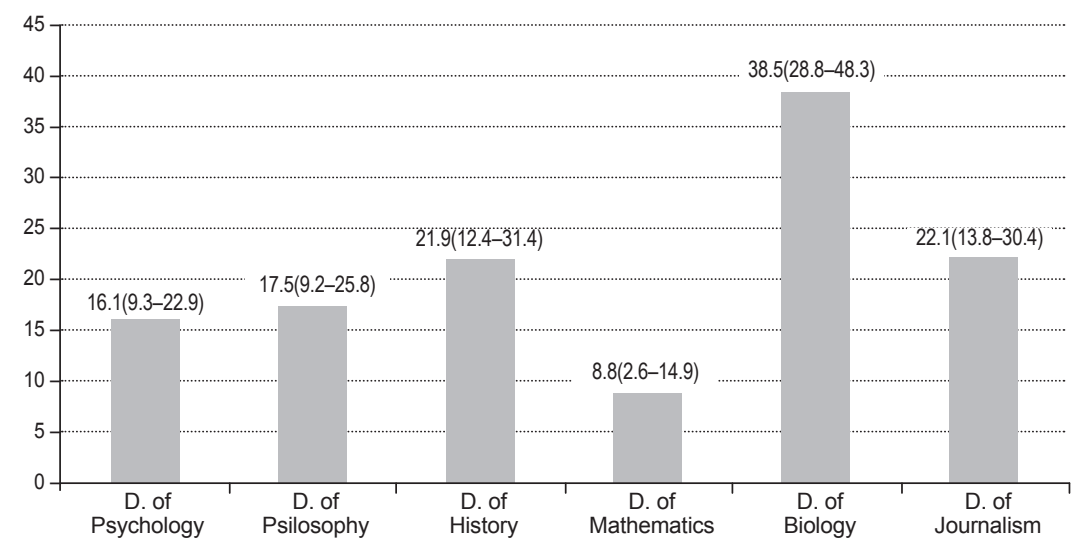

Figure 1. Percentage of students who were aware of the existence of biobanks by department, \% (D. = department). The difference in rates by department was statistically significant at $p \leq 0.001$.

The degree of the students' awareness did not correlate in any significant way with their sex or the number of years that they had already been at the university. Thus, we might assume that the students' awareness of the existence of biobanks was not directly linked to studying at the university. More likely, it was acquired through other channels, possibly through the media.

\section{Notions about readiness to become a biobank donor}

The majority of the students $(73.9 \%$ (70.2-77.6)) indicated that they would react favorably to an offer to donate some of their biological materials to a biobank. More specifically, every fifth student (22.9\% (19.4-26.5)) was absolutely certain that he/ she would do so if presented with the opportunity. Of all those who filled out a questionnaire, 5.4\% (3.5-7.3) indicated that they would categorically refuse to become such donors.

The most important kind of information that the students indicated they would need in order to make a decision about becoming donors was the specific goal of the research (mean 1.6 points out of a maximum of 2) (Figure 2). Other significant factors included the following: research methods, type of biological material collected (blood, saliva, etc.), and ability to donate samples anonymously. For the 
majority of those tested, the significant factors did not include payment for being a donor or the sources of research funding. In addition, the students did not consider approval of their close social circle an important factor in agreeing to become a donor. Apparently, the informants were planning to make such a decision on their own.

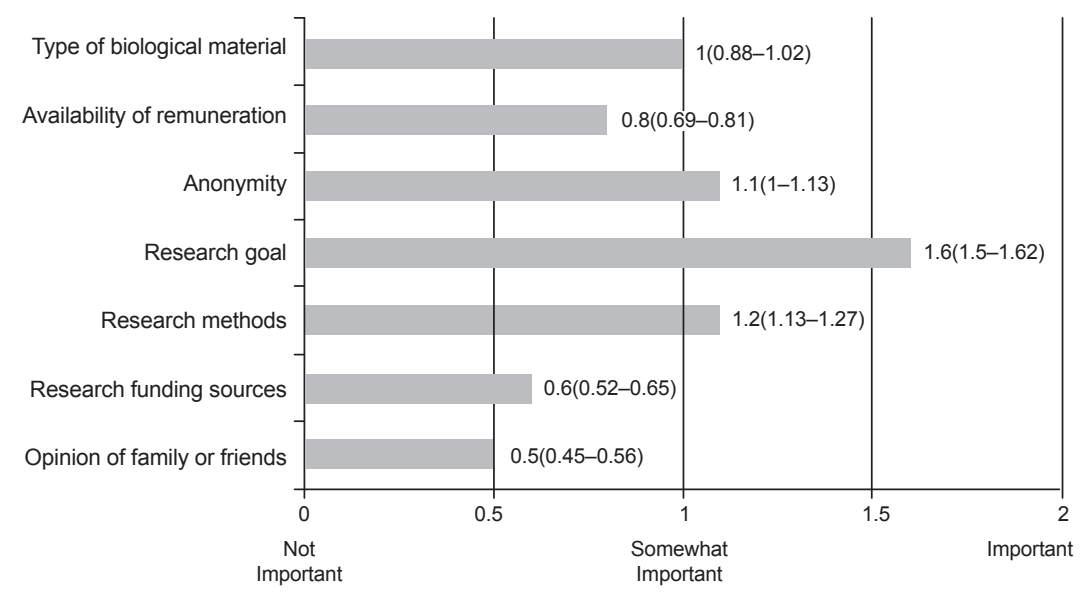

Figure 2. Importance of different kinds of information for decision-making about donorship to a biobank, $M(0-\min , 2-\max )$.

A small percentage of the informants (3.2\% (1.7-4.7)) also mentioned other factors that they considered important. Above all, these included the safety of the biological-material collection procedure and the ability to get feedback based on the results of the study.

On the whole, when making a decision about becoming donors, the women students thought that the goal of the proposed research was significantly more important (very important $68.9 \%(64.1-73.8)$ ) than the men did (56.1\% (48.1-64.1); $p$ $\leq 0.05)$; the men thought that the possibility of remuneration was more important (very important or somewhat important $71.6 \%(64.4-78.9)$ ), than the women did (58.8\% (53.7-63.9), $p \leq 0.01$ ), and the men also thought that knowledge about the organization funding the research was more important (very important or somewhat important $55.1 \%(47.1-63.1))$ than the women $\operatorname{did}(38.7 \%(33.6-43.8), p \leq$ $0.01)$.

\section{Factors in readiness to become a biobank donor}

In this study we put forward a hypothesis about a correlation between a person's readiness to become a biobank donor and sociodemographic characteristics, including value orientations, satisfaction with various aspects of one's life, and selfevaluation of one's qualities and traits.

However, the study did not confirm the existence of any sociodemographic characteristics that could predict one's readiness to become a biobank donor. Sex, age, year of study, religious affiliation-none of these factors correlated with readiness to become a donor in any significant way. Also, no significant correlations were found with one's self-evaluation of specific qualities or with one's satisfac- 
tion with life. In particular in our sample we did not find any correlation between participants' willingness to donate and how they rated their physical and mental health, sexual attractiveness, ability to withstand the difficulties of life, academic performance, or sociability. Readiness to donate also didn't correlate with participants' satisfaction with relationships, intimacy, material living standards, or job prospects.

The multidimensional model (Table 1) demonstrated significant correlations with several value orientations: the propensity to declare a willingness to become a biobank donor was demonstrated significantly more often by the students for whom some of the most important individual values were gaining knowledge and having an interesting job. At the same time, the value of leading a productive life correlated negatively with the intention to donate samples to a biobank.

Table 1. Multidimensional model of factors in readiness to become a biobank donor

\begin{tabular}{lcc}
\hline Variables & $\begin{array}{c}\text { Odds Ratio (OR) } \\
(\mathbf{9 5 \%} \mathbf{C I})\end{array}$ & $\begin{array}{c}\text { Adjusted Odds Ratio } \\
(\text { AOR) (95\% CI) }\end{array}$ \\
\hline Department of Biology (yes vs. no) & $2.784(1.743-4.448)^{* * *}$ & $2.459(1.501-4.030)^{* * *}$ \\
Department of Journalism (yes vs. no) & $0.512(0.279-0.939)^{\star}$ & - \\
Value = being healthy & $0.654(0.981-0.435)^{\star}$ & - \\
Value = having an interesting job & $1.695(1.128-2.544)^{\star}$ & $1.618(1.058-2.475)^{*}$ \\
Value = gaining knowledge & $1.834(1.178-2.857)^{* *}$ & $1.658(2.65-1.035)^{*}$ \\
Value = leading a productive life & $0.401(0.829-0.194)^{\star}$ & $0.396(0.188-0.833)^{\star}$ \\
\hline
\end{tabular}

${ }^{*}-\mathrm{p} \leq 0.05,{ }^{* *}-\mathrm{p} \leq 0.01,{ }^{* *}-\mathrm{p} \leq 0.001$

The most predictive factor in the students' readiness to become donors was studying in the Biology Department. This factor increased by 2.5 times the likelihood of a "yes" answer to the question about readiness to donate samples to a biobank. The existence of prior information about biobanking did not constitute a significant factor in one's readiness to become a donor, and this factor was not included in the final model. Thus, being a biology major constituted an independent factor in one's readiness to become a donor, and being ready to donate was not linked to higher awareness.

On the whole, the model is characterized by extremely low predictive ability, allowing us to predict less than $10 \%$ of the dependent variable dispersion (Nagelkerke R Square - 0.093), as well as by its correctly classifying $76.5 \%$ of all cases.

\section{Discussion}

The results of the study, which indicate a relatively high level of readiness to become biobank donors among young Russians (74\%), correlate with the results of a number of international studies, which show about $80 \%$ of the population willing to become donors (Budimir et al., 2011; Kettis-Lindblad et al., 2006; Porteri, Pasqualetti, Togni, \& Parker, 2014; Wendler, 2006;). Nevertheless, in our opinion, the study of the factors that play a role in one's readiness to become a donor is still 
relevant because this knowledge guarantees that biobanks can remain viable in the long term if they do not allow the level of readiness to decrease as a result of negative influences, such as by the media (creating myths, for example).

In spite of the fact that awareness of biobanks did not figure as a significant factor in the students' readiness to become donors, we should take into consideration the experience of Western societies and be wary of insufficient awareness about biobanking among the population, as well as of a deficit of trust in official medicine and public health services, as these constitute the main barriers to biobank donorship (Kettis-Lindblad et al., 2006). Also, among the potential risks associated with biobanking, researchers see donors' fears concerning breaches of confidentiality norms - the transfer of personal (genetic) data to third parties and, as a result, stigmatization of and discrimination against donors (Lipworth, Forsyth, \& Kerridge, 2011) - as up to $90 \%$ of potential donors are worried about their privacy (Budimir et al., 2011).

Our study did not reveal any influence of sociodemographic variables on one's willingness to become a donor, although it did reveal some gender differences in the biobank characteristics that were considered important by the students. Studies on attitudes toward biobank donation among different sociodemographic groups often contain highly contradictory conclusions. In particular, the correlation between one's willingness to be a donor and one's age is not clear-cut: a number of studies indicate an increase in readiness as one grows older (Kettis-Lindblad et al., 2006), while others indicate a decrease (Wakefield, Watts, Homewood, Meiser, \& Siminoff, 2010).

On the whole, based on the results of studies conducted in other countries, these are the key factors in creating positive attitudes toward becoming a biobank donor: altruism, reciprocity, expectations of personal benefit from a new form of therapy, availability of direct feedback based on the results of the research, the clinical encounter surrounding donation (e.g., a test or physical examination), financial remuneration (Lipworth et al., 2011). However, Hoeyer (2008) points out, on the basis of a critical review of relevant studies, that attitudes toward donation are rigidly determined by the type of biological material being collected and by the donor's status. Thus, cancer patients are more likely to agree to become donors, while, in cohort studies, representatives of the general population are less favorable toward the idea. And, finally, relatives of potential cadaveric donors are the least likely to grant permission. It might be thus assumed that the more pressing the need for the results of medical studies, the more likely the possibility of a person's having a favorable attitude toward becoming a donor.

This study demonstrated an extremely limited influence of value orientations on readiness to become a donor. A certain degree of predictive ability can be attributed only to the dominant role in the personality structure of the values of gaining knowledge and of having an interesting job (perhaps, taking into consideration the nature of the study target group, of having an academic career in research). Thus, it is difficult to offer a meaningful interpretation of the moderately negative correlation that was revealed to exist between one's readiness to become a donor and valuing leading a productive life value.

Our research also revealed that studying biology can be a factor in one's readiness to become a donor. It might be argued that students who enroll and study in 
the Department of Biology take part in a natural selection and self-selection process whose criteria include belief in the progress of biological science, biotechnology, and genetic engineering, as well as the absence of an irrational fear of science as a whole, and that these criteria allow the formation of favorable attitudes toward donation.

\section{Limitations}

This study has a number of limitations. It was conducted using data from a specific subgroup of the general populace, students, whose characteristics include a young age and a high level of education with an emphasis on academic learning. As results of Western studies indicate, a high level of education invariably leads to an increase in the level of readiness to become a biobank donor (Hoeyer, 2008; Wakefield et al., 2010). Also, as in the majority of studies on this subject, a significant limitation of our study consisted in the target variable used-that is, one's attitude toward becoming a donor. It is well known that one's readiness or intention to engage in an activity cannot always be seen as a perfect predictor of real behavior. Therefore we must realize that in reality the percentage of people who agree to and actually donate their biological materials to a biobank may turn out to be significantly lower.

Future directions of biobanking attitudes and behavior in Russia might be expanded to studying different groups of participants, including hospital patients with different conditions. From a psychological perspective it seems important to further study the motivation behind the willingness to become a biobank donor: Is it influenced by the same factors as other altruistic behaviors (blood donorship, giving to charity, for example), or is it of a different nature?

\section{Conclusion}

This study demonstrated that today sociopsychological attitudes among the general population (at least among the subgroup studied, students) do not pose a problem for further development of biobanking in Russia. Ours is the first study in Russia that has tried to offer an empirical evaluation of attitudes toward biobank donation among young Russians.

\section{Acknowledgments}

This study was supported by a grant from the Russian Science Foundation (project no. 14-50-00069), St. Petersburg State University.

\section{References}

Budimir, D., Polašek, O., Marušić, A., Kolčić, I., Zemunik, T., Boraska, V., . . Rudan, I. (2011). Ethical aspects of human biobanks: A systematic review. Croatian Medical Journal, 52(3), 262-279. doi: 10.3325/cmj.2011.52.262

Buikin, S. V., Bragina, E. U., Koneva, L. A., \& Puzyrev, V. P. (2012). Bazy dannyh kollekcij biologicheskogo materiala: organizacija soprovoditelnoj informacii [Databases of biological material collections: Organizing reference information]. Sibirskij Meditsinskij Bjulleten [Siberian Medicine Bulletin], 1, 111-120. 
Feigin, S., Owens, G., \& Goodyear-Smith, F. (2014). Theories of human altruism: A systematic review. Annals of Neuroscience and Psychology, 1(1). Retrieved from http://ww.vipoa.org/ neuropsychol

Gaskell, G., \& Gottweis, H. (2011). Biobanks need publicity. Nature, 471(7337), 159-160. doi: $10.1038 / 471159 \mathrm{a}$

Hoeyer, K. (2008). The ethics of research biobanking: A critical review of the literature. Biotechnology and Genetic Engineering Reviews, 25(1), 429-452. doi: 10.5661/bger-25-429

Kettis-Lindblad, Å., Ring, L., Viberth, E., \& Hansson, M. G. (2006). Genetic research and donation of tissue samples to biobanks. What do potential sample donors in the Swedish general public think? European Journal of Public Health, 16(4), 433-440. doi: 10.1093/eurpub/ cki198

Lipworth, W., Forsyth, R., \& Kerridge, I. (2011). Tissue donation to biobanks: A review of sociological studies. Sociology of Health \& Illness, 33(5), 792-811. doi: 10.1111/j.1467-9566. 2011.01342.x

O’Doherty, K. C., \& Hawkins, A. (2010). Structuring public engagement for effective input in policy development on human tissue biobanking. Public Health Genomics, 13(4), 197-206. doi: $10.1159 / 000279621$

Porteri, C., Pasqualetti, P., Togni, E., \& Parker, M. (2014). Public's attitudes on participation in a biobank for research: An Italian survey. BMC Medical Ethics, 15, 81-90. doi: 10.1186/14726939-15-81

Riegman, P. H., Morente, M. M., Betsou, F., de Blasio, P., Geary, P., \& Marble Arch International Working Group on Biobanking for Biomedical Research. (2008). Biobanking for better healthcare. Molecular Oncology, 2(3), 213-222. doi: 10.1016/j.molonc.2008.07.004

Serepkaite, J., Valuckiene, Z., \& Gefenas, E. (2014). "Mirroring” the ethics of biobanking: What should we learn from the analysis of consent documents? Science and Engineering Ethics, 20(4), 1079-1093. doi: 10.1007/s11948-013-9503-y

Sudlow, C., Gallacher, J., Allen, N., Beral, V., Burton, P., Danesh, J., ... Liu, B. (2015). UK Biobank: An Open Access resource for identifying the causes of a wide range of complex diseases of middle and old age. PLoS Medicine, 12(3), 1-10. doi: 10.1371/journal.pmed.1001779

Thompson, S. G., \& Willeit, P. (2015). UK Biobank comes of age. Lancet, 386(9993), 509-510. doi: 10.1016/S0140-6736(15)60578-5

Wakefield, C., Watts, K., Homewood, J., Meiser, B., \& Siminoff, L. (2010). Attitudes toward organ donation and donor behavior: A review of the international literature. Progress in Transplantation, 20(4), 380-391. doi: 10.7182/prtr.20.4.p54651601pg80183

Wendler, D. (2006). One-time general consent for research on biological samples. BMJ, 332, 544-547. doi: 10.1136/bmj.332.7540.544

Original manuscript received October 22, 2015 Revised manuscript accepted December 03, 2015 First published online June 30, 2016 